\title{
QUALITY ANALYSIS OF BLOOD COMPONENT (PRBC AND PLATELET CONCENTRATES): A STUDY FROM A TERTIARY CARE TEACHING HOSPITAL OF KUMAON REGION OF UTTARAKHAND
}

\author{
Saloni Upadhyay', Tanuja Pangtey² \\ ${ }_{1}^{1}$ Associate Professor, Department of Pathology, Government Medical College, Haldwani, Uttarakhand, India. \\ ${ }^{2}$ Senior Resident, Department of Pathology, Government Medical College, Haldwani, Uttarakhand, India.
}

\section{ABSTRACT}

\section{BACKGROUND}

Quality Analysis of blood depends upon three concepts viz. quality control, quality assurance \& quality management. Quality control measures standard practice in their operations eg. reagent quality control, clerical checks, visual inspections along with measurements like temperature reading on refrigerators and volume of cell counts performed on finished blood components. Quality assurance, on the other hand include recording reviews, monitoring of quality indicators and internal assessments. Quality management is an inter-related processes in the context of organization and its relations with customers \& suppliers. A study of quality control for blood components in a tertiary care centre of Kumaon region of Uttarakhand has been presented here to provide a benchmark and evaluation for its maintenance and sustainability in blood bank of Uttarakhand region, catering to a large geographic area. An annual qualitative study is thus undertaken regarding assessment of various blood parameters in quality control sample during the period of Jan to Dec 2015.

\section{METHOD AND MATERIAL}

The sample of 1.2 and $2.1 \%$ of total blood received were tested for quality control for PRBC and platelets respectively. Parameters like whole blood of CPD, hematocrit platelet \& WBC, Red cell (PRBC) was done in the sample. Statistics for quality analysis - Mean, range and standard deviation were obtained using SPSS version 12.

\section{RESULT}

The quality control data for whole blood unit, buffy coat, platelet and platelet concentrates were found to be within range for standard criteria and thus of optimum quality in our setting. The samples were having minimal leukocyte count thus safer for transfusion.

\section{CONCLUSION}

Periodic re-assessment and quality checking should be a departmental protocol and care should be made to use standard and relevant techniques and criteria for quality assessment. Adherence to standard values and maintenance of quality should be periodically ensured by objective analysis.

\section{KEYWORDS}

Quality Control, Blood Component Transfusion, Blood Banks, Cell Separation.

HOW TO CITE THIS ARTICLE: Upadhyay S, Pangtey T. Quality analysis of blood component (PRBC and platelet concentrates): a study from a tertiary care teaching hospital of Kumaon region of Uttarakhand. J. Evolution Med. Dent. Sci. 2016;5(23):1210-1212, DOI: $10.14260 /$ jemds/2016/282

\section{INTRODUCTION}

The transfusion practices are based on providing right blood to right person at right place and time. ${ }^{1}$ Blood banks rely on component separation practices in order to use the blood to its utmost use. ${ }^{2}$ Besides it, appropriate temperature maintenance is required for viability and longevity of blood and its components under various parameters. ${ }^{3}$ Quality control of the procedures at regular interval is warranted to check adequacy and safety of the transfusion operations and are part of good transfusion practices. While centers have their reports and audits of quality control outcomes as standard practice, one in a tertiary centre of Uttarakhand holds importance and has never been published to the best of knowledge of authors.

Financial or Other, Competing Interest: None.

Submission 23-02-2016, Peer Review 07-03-2016,

Acceptance 09-03-2016, Published 18-03-2016.

Corresponding Author:

Saloni Upadhyay,

Associate Professor,

Department of Pathology,

Government Medical College,

Haldwani,

Uttarakhand, India

E-mail: blood.bank.009@gmail.com

DOI: $10.14260 /$ jemds/2016/282

\section{MATERIAL AND METHODS}

Healthy screened donors $(>50 \mathrm{Kg}$ ) were part of the study during period of Jan 2015 to Dec 2015 and were recruited through routine departmental donations or voluntary donation in camps.

Preparation of whole blood- The blood bag of $350 \mathrm{~mL}$ was collected in quadruple bag system (Terumo Penpol). Holding time of 2-4 hrs. followed by centrifugation (3100 rpm, $9 \mathrm{~min}, 22^{\circ} \mathrm{C}$ ) was performed. The blood was separated into three components, viz. Packed Red Blood Cells (PRBC), Buffy Coat (BC) and plasma. The procedure was done with the help T-ACE I and II. BC was subjected to resting period hrs. and centrifuged at $850 \mathrm{rpm}$ for 6 minutes at $22^{\circ} \mathrm{C}$. Platelet concentrates now obtained after the procedure.

Sampling analysis of units - $>1 \%$ of total units separated and subjected to quality control analysis.

Measurement of parameters like whole blood of CPD, haematocrit (Hct), platelet and WBC, Red cell (PRBC) was done.

Statistics for quality analysis-Mean, range and standard deviation using SPSS version 12 .

\section{RESULT}

A total collection of 10,917 units of blood was done, which 
include 3531 (32.3\%) units of whole blood in single bags and 7386 units were collected in quadruple bag. PRBC 7386 units $(67.6 \%)$ and platelet 5515 units (50.5\%) were extracted out of these collections.

Units $(1.2 \%)$ and $(2.1 \%)$ were subjected to quality analysis for PRBC and platelets respectively.

Quality control for whole blood unit- Whole blood-QC in our data was found to be under satisfactory range as haematocrit level of $43.7 \%$ and haemoglobin \% of 63 are noted. Cell counts (WBC, platelet and RBC) are also noted to be in routine range (Table 1 ).

Similarly, the QC for buffy coat in the same sample was noted to be within normal range with respect to cell counts, volume and haematological values as depicted in (Table 2).

Quality control for PRBC- No established guidelines as per DCA are available. PRBC-QC in present study can be considered satisfactory.

\begin{tabular}{|c|c|c|c|c|c|c|}
\hline Parameters & $\begin{array}{c}\text { Volume Concentration } \\
\text { with CPD }\end{array}$ & Hct\% & $\begin{array}{c}\text { Hb\% } \\
(\mathbf{g} / \mathbf{b a g})\end{array}$ & $\begin{array}{c}\text { RBC } \\
(\mathbf{x 1 0 . 1 2})\end{array}$ & $\begin{array}{c}\text { Platelet } \\
(\mathbf{x 1 0 . 1 1})\end{array}$ & $\begin{array}{c}\text { WBC } \\
(\mathbf{x 1 0 . 9})\end{array}$ \\
\hline Mean \pm SD & $410 \pm 8.1$ & $43.7 \pm 3.2$ & $63 \pm 4.4$ & $1.99 \pm 0.3$ & $0.97 \pm 0.3$ & $3.4 \pm 0.7$ \\
\hline Range & $391-522$ & $38-52.5$ & $56.7-74.2$ & $1.57-2.39$ & $0.5-1.7$ & $2-4.9$ \\
\hline \multicolumn{2}{|r}{} \\
\hline
\end{tabular}

\begin{tabular}{|c|c|c|c|c|c|c|c|}
\hline Parameters & $\begin{array}{c}\text { Volume } \\
(\mathbf{m l} .)\end{array}$ & $\begin{array}{c}\text { Platelet } \\
(\mathbf{x 1 0 . 1 1})\end{array}$ & $\begin{array}{c}\text { Platelet\% } \\
\text { recovery }\end{array}$ & $\begin{array}{c}\text { WBC } \\
\left.(\mathbf{x 1 0})^{-}\right)\end{array}$ & $\begin{array}{c}\text { WBC\% } \\
\text { recovery }\end{array}$ & $\begin{array}{c}\text { RBC } \\
(\mathbf{x 1 0 . 1 2})\end{array}$ & $\begin{array}{c}\text { RBC\% } \\
\text { loss }\end{array}$ \\
\hline Mean \pm SD & $96.4 \pm 6.1$ & $0.89 \pm 0.2$ & $91.7 \pm 7.6$ & $2.52 \pm 0.5$ & $62.7 \pm 13.3$ & $0.65 \pm 0.13$ & $15 \pm 5.47$ \\
\hline Range & $79-105$ & $0.58-1.2$ & $59.2-98.4$ & $1.53-4.1$ & $48.3-78.4$ & $0.4-0.9$ & $9.8-26.1$ \\
\hline \multicolumn{7}{|c|}{ Table 2: Volume and Haematological Values of Buffy Coat Units (n=58) } \\
\hline
\end{tabular}

\begin{tabular}{|c|c|c|c|c|c|c|}
\hline Parameters & $\begin{array}{c}\text { Volume Concentration } \\
\text { SAGM }\end{array}$ & Hct\% & $\begin{array}{c}\text { Hb\% } \\
(\mathbf{g} / \mathbf{b a g})\end{array}$ & $\begin{array}{c}\text { RBC } \\
(\mathbf{x 1 0 . 1 2})\end{array}$ & $\begin{array}{c}\text { RBC } \\
\text { recovery }\end{array}$ & $\begin{array}{c}\text { WBC } \\
\mathbf{( x 1 0 . 9}\end{array}$ \\
\hline Mean \pm SD & $285 \pm 24.3$ & $54 \pm 4.2$ & $52.5 \pm 57$ & $1.77 \pm 0.37$ & $77.7 \pm 7.89$ & $1.3 \pm 0.63$ \\
\hline Range & $198-350$ & $41-69$ & $38-59.2$ & $1.04-2.07$ & $66.7-86$ & $0.3-3.4$ \\
\hline EC criteria & NA & 85.1 & 92.9 & NA & NA & 42 \\
\hline \multicolumn{2}{r|}{ Table 3: Quality of Red Cell Concentration (n=260) } \\
\hline
\end{tabular}

\begin{tabular}{|c|c|c|c|c|c|}
\hline Parameters & $\begin{array}{c}\text { Volume } \\
(\mathbf{m l})\end{array}$ & $\mathbf{p H}$ & $\begin{array}{c}\text { Platelet } \\
(\mathbf{x 1 0 1 1})\end{array}$ & $\begin{array}{c}\text { Platelet\% } \\
\text { recovery }\end{array}$ & $\begin{array}{c}\text { WBC } \\
(\mathbf{x 1 0})\end{array}$ \\
\hline Mean \pm SD & $54 \pm 7.6$ & $7.03 \pm 0.3$ & $5.5 \pm 2.8$ & $5.58 \pm 13.5$ & $3.5 \pm 2.7$ \\
\hline Range & $79-105$ & \multicolumn{2}{|c|}{$0.58-1.2$} & $59.2-98.4$ & $1.53-4.1$ \\
\hline \multicolumn{2}{|r|}{ Table 4: Quality for Platelet Concentrates (n=268) } \\
\hline
\end{tabular}

\section{DISCUSSION}

Quality concepts depend upon quality control, quality assurance and quality management and their maintenance. Quality control involves initiatives to ensure quality of blood product for its varied usage. Improved quality testing over the periods has resulted in safer transfusion practices and decreased adverse outcomes. ${ }^{4} \mathrm{~A}$ standard practice in the west, it still is a new concept in developing countries because of poor laboratory settings and non-standard devices. Studies have been done to determine causes of transfusion associated untoward reactions and preventive measures have also been suggested. ${ }^{5}$ Haemovigilance, as a concept, is growing popularity and appears to be a future directive. 6 Various techniques like leuko-reduction have been reported to make blood transfusion safer. 7 The components in our study had minimal leukocytes thus providing enhanced effects and safety.

The overall audit of quality control met standard criteria and normal limits in areas with no standard criteria defined. The periodic check for quality of haematological values inside blood banks should be done periodically and that period may be planned as per the volume and requirement of work. This practice is essential for ensuring that the operative functioning of blood banks is satisfactory and matches industry standards. Apart from this, compliant work ethics and universal safety measures as per national or international guidelines should be practiced for the safety of donor and healthcare personnel. One important finding in our study is reconfirmation of the fact that leuko-depletion standard is efficient in our setup and which is standard practice worldwide with reported advantages for recipient safety. Platelet and platelet concentrates play a vital role in Indian transfusion scene, especially in times of summer as dengue cases rise to epidemic proportion and need based requirement of storage, maintenance and supply of platelets is highly recommended.

The quality control in this regard should be adjusted for potential seasonal increase in workload and measures taken for efficient delivery of platelets of utmost quality to rightful recipient. Plasma requirements are satisfactorily met by our department for various medical requirements on routine basis and the quality control data supports their quality meeting standard cut-off. The overall quality study was found to be 
satisfactory in our department and longevity of it shall depend on continuous improvement and strict review regimen. Apart from it, a multicentre collaborative work can be undertaken to develop Indian guidelines for standard values and recommendations based on our data for effective delivery of blood products.

\section{CONCLUSION}

A regular updation of quality control assessment of transfusion services is critical for establishment of objectives of good transfusion practices. A study of this kind is essential to form basis of future work in this area. This is the first study of such type in the tertiary care centre and teaching hospital in Kumaon region of Uttarakhand as per our knowledge.

\section{REFERENCES}

1. Letowska M. Patient-specific component requirements: right blood, right patient, right time, right place. ISBT Sci Ser 2009;4:52-5.
2. Hardwick J. Blood processing: introduction to blood transfusion technology. ISBT Sci Ser 2008;3:148-76.

3. Hardwick J. Blood storage and transportation. ISBT Sci Ser 2008;3:177-96.

4. Au Buchon JP, Kruskall MS. Transfusion safet: realigning efforts with risks. Transfusion 1997;37:1211-16.

5. Williamson LM, Lowe S, Lowe EM, et al. Serious hazard of transfusion (SHOT) initiative: analysis of the first two annual reports. BMJ 1999;309:16-9.

6. De Vries RR, Faber JC, Strengers PF. Hemovigilance: an effective tool for improving transfusion practice. Vox Sang 2011;100:60-7.

7. Basu D, Kulkarni R. Overview of blood components and their preparations. Indian J Anaesth 2014;58(5):529-537. 